\title{
A Study on Small-Scale Creep near a Crack Tip at High Temperatures
}

by

\author{
Shiro KUBO*
}

\author{
Key words: Creep crack, Small-scale creep, Modified J-integral, Creep J-integral, C*-integral, Near-tip field \\ Large-scale creep, Transition time, Fracture mechanics, High temperature strength
}

\section{Introduction}

This article introduces a paper on the small-scale creep effect in creep crack initiation and growth. The paper was published in the Journal of Society of Materials Science, Japan. Although it is written in Japanese, it is worldly well-known in the research area of high temperature fracture mechanics, because of its simple and useful equation describing the small-scale creep condition. The derivation of the equation is described below, together with the states of the arts in creep crack research, and the episodes about the paper.

Due to recent severe economical and environmental requirements for plants and their components operated at high temperatures, their operating temperatures have increased considerably. Many of the plants and their components are then operated in the creep range where creep deformation is significant, and are also subjected to non-steady loads. To evaluate their safety, creep effects in addition to fatigue effects are essential. Since cracking is observed before fracture, the quantitative evaluation can be constructed by applying the fracture mechanics, which was found useful in evaluating crack initiation and ductile crack growth at room temperature.

Application of the fracture mechanics to high temperature crack problems started from the characterization of high cycle fatigue crack growth using the stress intensity factor $K$. For the evaluation of creep crack growth, $K$ was used in the early stage of research ${ }^{1), 2)}$. Some researchers claimed the superiority of the net section stress for correlating the creep crack growth rate. Considering the severe nonlinearity in the creep deformation, the present author ${ }^{3)-7)}$ proposed the modified J-integral, $J$ ' by applying the similarity between the steady-state creep and the nonlinear elasticity to the J-integral concept for nonlinearly elastic materials. The modified J-integral, $J$ ' was also called the creep J-integral, $J^{*}$. Proposal of the modified J-integral was included in the draft paper of the proceedings of 1974 Symposium $^{8)}$, but unfortunately the proposal of $J$ ' was deleted in the final version of the paper due to page limit. This may be why the paper is referred in a book on high temperature strength ${ }^{9)}$ as a paper proposing the modified J-integral. Two years later the $\mathrm{C}^{*}$-integral, which was identical with the modified J-integral $J$, was proposed by several research groups ${ }^{10), 11)}$.

The difficulty in the evaluation of the modified J-integral, $J^{\prime}$ hindered the application of $J$ ' to creep crack growth. Simple evaluation formulae $e^{4), 12)-14)}$ for $J^{\prime}$ promoted wide application of $J$ ' to creep crack growth. Comparison of the formulae is found in a review article $e^{15)}$.

Many papers were published on the governing mechanical parameter of the creep crack growth rate ${ }^{16)-19)}$. Intensive discussions were given at the 1980 Creep Conference ${ }^{20)}$ and finally it was internationally accepted that the modified J-integral, $J^{\prime}$ ( or $J^{*}$ and $C^{*}$ ) was superior to $K$ and net section stress for the correlation of creep crack growth rate. An analysis $^{21)}$ of creep crack growth rate was made based on singular stress and strain-rate fields expressed in terms of $J$ '.

$J$ ' was defined based on the assumption of extensive creep conditions, where creep strains overwhelm elastic and plastic strains. In the early stage of load application, however, and creep dominating region is confined by an elastic region, where elastic strains are predominant. This situation can be called the small-scale creep. The present author tried to figure out this situation, but found out that the problem was a tough one. Eventually he was hit by a car coming just in front, when he was driving a motorcycle. He was lucky that he did not die, but his knee was considerably injured and he could not walk. He was so optimistic to think he had enough time to think over the problem. But the condition of the knee got worse, which did not allow him to concentrate on the problem.

Somehow he recovered from the injury and then restarted the study. He got an idea of applying the approximate path-independence of the J-integral, and obtained an equation of near-tip $J$ ' under the small-scale creep conditions. This equation predicted a seemingly strange behavior that $J$ ' went to infinity at load application. Since he was not confident

\footnotetext{
+ Received Aug. 10, 2020 (2021 The Society of Materials Science, Japan

* Member : Dept. of Mech. Eng., Graduate School of Eng., Kobe University, Nada-ku, Kobe 657-8501 Japan

Professor Emeritus, Osaka University
} 
about the equation, he conducted finite element analyses. The equation gave an excellent agreement with the finite element results. Then he wrote a preprint ${ }^{22}$ ) (called 1979 preprint hereafter) for a JSME meeting.

At exactly the same time, he was preparing a sabbatical visit at Brown University to work with Professor Jim Rice. He was excited to know that Professor Hermann Riedel and Professor Jim Rice were studying on the same problem. He wrote an English version of the 1979 preprint and sent it to them, without noticing the importance of the equation and the meaning of showing the English version.

Then he started to write a paper on the small-scale creep $^{23)}$ for the Journal of Society of Materials Science, Japan (JSMS) in a rush. He wanted to get it published in 1980, knowing that Riedel was writing a paper on the small-scale creep. Ironically he proofread the Japanese paper when he was staying at Brown, despite the advice "write the paper in English" of a Rice's student, Mr. A.J. Rosakis, who is currently a Professor at California Institute of Technology.

Referees' comments and suggestions were severe and requested reform of the paper. The author reformed the paper in accord with the comments and suggestions to circumvent any delay in the publication. This is the reason why the paper has many footnotes and a long appendix. The paper has many discussions, which may be a reflection of suggestion "think out" of Professor Ben Freund, who was the chairperson of the Division of Engineering, Brown University. Actually the JSMS paper ${ }^{23)}$ (called 1980 paper hereafter) was published in 1980. The paper of Riedel and Rice ${ }^{24)}$ was published in the same year.

The basic assumptions and results of in the paper are described in the followings.

\section{Basic Assumptions Used in the Small-Scale Creep Formulation}

Consider a creep crack in a two-dimensional body. When the loading time $t$ is small, the creep strain develops only near the crack tip. The region where the creep strain dominates is well-contained in the elasticity singular stress field. To formulate this small-scale creep condition, the following assumptions are used.

(1) The creep crack is stationary.

(2) Strain $\varepsilon$ is composed of its elastic component $\varepsilon_{e l}$ and creep component $\varepsilon_{c r}$ :

$$
\varepsilon=\varepsilon_{e l}+\varepsilon_{c r}
$$

(3) The following elastic singular stress and strain fields develop far from the crack tip.

$$
\begin{aligned}
& \sigma_{i j}=K f_{i j}(\theta) / \sqrt{2 \pi r} \\
& \varepsilon_{i j}=K g_{i j}(\theta) /(\sqrt{2 \pi r} E)
\end{aligned}
$$

Here $K$ denotes the stress intensity factor and $E$ is Young's modulus. Polar coordinates $r, \theta$ with origin at with the crack tip are used, $f_{i j}(\theta)$ and $g_{i j}(\theta)$ being eigen functions expressing the $\theta$-distributions of elastic singular stress and strain.

Assumption (3) is similar to that used in the small-scale yielding.

\subsection{Stress and Strain Fields near a Crack Tip under the} Norton Type Creep Law

In this chapter the creep strain rate $\dot{\varepsilon}_{c r}$ is given by the following Norton type creep law with material constants $A$ and $n$.

$$
\dot{\varepsilon}_{c r}=A \sigma^{n}
$$

By integrating Eq. (3) with $t$ to obtain $\varepsilon_{c r}$, and introducing $\varepsilon_{c r}$ into Eq. (1), we can obtain,

$$
\begin{aligned}
\varepsilon & =\varepsilon_{e l}+\int_{0}^{t} A[\sigma(s)]^{n} d s \\
& =\sigma(t) / E+A F(t)[\sigma(t)]^{n}
\end{aligned}
$$

Here $F(t)$ is given by,

$$
F(t)=\int_{0}^{t}[\sigma(s) / \sigma(t)]^{n} d s
$$

Generally function $F(t)$ depends on location. In the area far from the crack tip, $\sigma(t)$ is small and therefore the second term involving $F(t)$ in Eq. (4) does not give significant contribution. In the area near the crack tip singular stress field prevails and therefore proportional loading is attained. Then the dependence of $F(t)$ on location can be assumed to be small, and the stress-strain relation is the same as that of nonlinear elastic material for which Rice's J-integral ${ }^{25)}$ is applicable. By referring to the HRR singular stress field for nonlinear elastic material ${ }^{26), 27)}$, the stress and strain fields near the crack tip are expressed in terms of $J$ as,

$$
\begin{aligned}
\sigma_{i j} & =[J /\{\operatorname{IAF}(t) r\}]^{1 /(n+1)} \tilde{\sigma}_{i j}(\theta) \\
\varepsilon_{i j} & =A F(t)[J /\{\operatorname{IAF}(t) r\}]^{n /(n+1)} \tilde{\varepsilon}_{i j}(\theta)
\end{aligned}
$$

Here $\tilde{\sigma}_{i j}(\theta)$ and $\tilde{\varepsilon}_{i j}(\theta)$ are eigen functions expressing the plastic singular stress and strain fields, and $I$ is a constant dependent on $n$. From assumption (3), $J$ is equal to the elastic J-integral which can be expressed in terms of $K$ for the mode I crack as,

$$
J=J_{e l}=K_{I}^{2} / E^{\prime}
$$

Here $E^{\prime}$ is given by $E$ and Poisson's ratio $v$ as follows:

$$
\begin{array}{ll}
E^{\prime}=E & \text { (for plane stress) } \\
E^{\prime}=E /\left(1-v^{2}\right) & \text { (for plane strain) }
\end{array}
$$

Assume that $J_{e l}$ is proportional to $t^{\alpha}$, and therefore load $P$ is proportional to $t^{\alpha / 2}$ with a non-negative constant $\alpha$ as in Fig. 1:

$$
\begin{array}{ll}
P=B_{1} t^{\alpha / 2} & \left(B_{1}: \text { constant }\right) \\
J_{e l}=B_{2} t^{\alpha} & \left(B_{2}: \text { constant }\right)
\end{array}
$$

Substituting Eq. (9) into Eq. (6), the stress is proportional to $\left\{t^{\alpha} / F(t)\right\}^{1 /(n+1)}$. Then Eq. (5) reduces to,

$$
F(t)=\int_{0}^{t}\left[(s / t)^{\alpha} F(t) / F(s)\right]^{n /(n+1)} d s
$$

The solution of this integral equation is given as,

$$
F(t)=\{(n+1) /(1+\alpha n)\} t
$$

By substituting Eq. (10) into Eq. (6), the stress, strain and strain-rate fields near the crack tip are expressed as, 


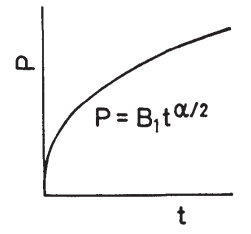

(a)

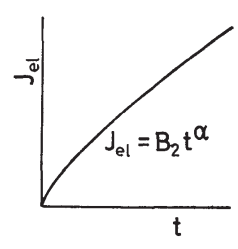

(b)
Fig. 1 Assumed change in $P$ and $J_{e l}$ with time.

$$
\begin{aligned}
& \sigma_{i j}=\left[(1+\alpha n) J_{e l} /\{I A(n+1) t r\}\right]^{1 /(n+1)} \tilde{\sigma}_{i j}(\theta) \\
& \varepsilon_{i j}=\{A(n+1) t /(1+\alpha n)\}[]^{n /(n+1)} \tilde{\varepsilon}_{i j}(\theta) \\
& \dot{\varepsilon}_{i j}=A[]^{n /(n+1)} \tilde{\varepsilon}_{i j}(\theta)
\end{aligned}
$$

The expressions in brackets [] in the second and the third equations are the same as in the first one, and therefore are omitted for brevity. Similar omission will be applied hereafter.

Since the creep strain is predominant near the crack tip, the modified J-integral, $J^{\prime}$ can be defined, and the near tip stress and strain rate can be expressed in terms of $J^{\prime}$ as,

$$
\begin{aligned}
& \sigma_{i j}=\left[J^{\prime} /\{I A r\}\right]^{1 /(n+1)} \tilde{\sigma}_{i j}(\theta) \\
& \dot{\varepsilon}_{i j}=A[]^{n /(n+1)} \tilde{\varepsilon}_{i j}(\theta)
\end{aligned}
$$

By comparing Eqs. (11) and (12), the following expression for $J^{\prime}$ can be obtained.

$$
\begin{aligned}
J^{\prime} & =(1+\alpha n) J_{e l} /\{(n+1) t\} \\
& =(1+\alpha n) B_{2} t^{\alpha-1} /(n+1)
\end{aligned}
$$

Under constant load, $\alpha=0$ and Eqs. (10) and (13) reduce to,

$$
\begin{aligned}
& F(t)=(n+1) t \\
& J^{\prime}=J_{e l} /\{(n+1) t\}
\end{aligned}
$$

\subsection{Stress and Strain Fields near a Crack Tip under}

\section{Time-Hardening Creep Law}

The modified J-integral, $J$ ' can be extended to several hardening creep laws ${ }^{5)}$. The time-hardening creep law and the strain-hardening creep law are typical ones. In this section the creep strain rate is given by the former one. When creep strain under constant stress is expressed by

$$
\varepsilon_{c r}=A\left(t / t_{0}\right)^{m-1} t \sigma^{n} \quad\left(t_{0}: \text { constant }\right),
$$

the following time-hardening law is frequently used.

$$
\dot{\varepsilon}_{c r}=A m\left(t / t_{0}\right)^{m-1} \sigma^{n}
$$

By applying the approximate path-independence of the J-integral as in the preceding chapter, one can obtain the following equation.

$$
F(t)=\{m(n+1) /(m+\alpha n)\} t\left(t / t_{0}\right)^{m-1}
$$

The near-tip stress and strain-rate are obtained by substituting Eq. (18) into Eq. (6):

$$
\begin{aligned}
& \sigma_{i j}=\left[(m+\alpha n) J_{e l} /\left\{\operatorname{IAm}(n+1) t\left(t / t_{0}\right)^{m-1} r\right\}\right]^{1 /(n+1)} \tilde{\sigma}_{i j}(\theta) \\
& \dot{\varepsilon}_{i j}=A m\left(t / t_{0}\right)^{m}[]^{n /(n+1)} \tilde{\varepsilon}_{i j}(\theta)
\end{aligned}
$$

The modified J-integral, $J$ ' can be defined near the crack tip ${ }^{5)}$, where the creep strains dominate, and $J^{\prime}$ can be given as,

$$
\begin{aligned}
J^{\prime} & =(m+\alpha n) J_{e l} /\{(n+1) t\} \\
& =(m+\alpha n) B_{2} t^{\alpha-1} /(n+1)
\end{aligned}
$$

\subsection{Stress and Strain Fields near a Crack Tip under} Strain-Hardening Creep Law

From Eq. (16) the strain-hardening creep law can be introduced, which gives the creep strain rate as,

$$
\dot{\varepsilon}_{c r}=A^{1 / m} m\left(\varepsilon_{c r} / t_{0}\right)^{(m-1) / m} \sigma^{n / m}
$$

By applying the assumption of path-independence of the J-integral, one can obtain the following equation.

$$
F(t)=\{m(n+1) /(m+\alpha n)\}^{m} t\left(t / t_{0}\right)^{m-1}
$$

The near-tip stress and strain-rate are obtained by substituting Eq. (22) into Eq. (6):

$$
\begin{aligned}
& \sigma_{i j}=\left[(m+\alpha n)^{m} J_{e l} /\left\{\operatorname{IAm}^{m}(n+1)^{m} t\left(t / t_{0}\right)^{m-1} r\right\}\right]^{1 /(n+1)} \tilde{\sigma}_{i j}(\theta) \\
& \dot{\varepsilon}_{i j}=A m^{m}\left\{(n+1) /(m+\alpha n)^{m-1}\left(t / t_{0}\right)^{m-1}[]^{n /(n+1)} \tilde{\varepsilon}_{i j}(\theta)\right.
\end{aligned}
$$

The modified J-integral, $J$ ' can be defined for the strain-hardening material if proportional loading holds ${ }^{5}$, and $J$ ' near the crack tip where the creep strains dominate can be given by Eq. (20) again.

It is worth noting that $J^{\prime}$ does not depend on $A$ and the value of $J$ ' change with time even when $J_{e l}$ and therefore $K$ is constant.

\section{Comparison with Finite Element Solutions}

To examine the validity of the equations of near-tip $J$, finite element calculations for a center-cracked $(\mathrm{CN})$ plate under tension were made. Due to symmetry, only a quarter of the specimen was analyzed. Norton's creep and constant load are employed in the calculation:

$$
m=1, \alpha=0
$$

The ratio of crack length $2 a$ to plate width $2 W$ was 0.4 , and the ratio of plate length $2 h$ to plate width $2 W$ was set to 2 . The creep component $n$ was 9 .

The modified J-integral, $J$ ' was evaluated based on the following line integral definition.

$$
J^{\prime}=\int_{\Gamma}\left(W^{\prime} d x_{2}-T_{i} \partial \dot{u}_{i} / \partial x_{1} d \Gamma\right)
$$

Here $x_{1} x_{2}(=x y)$ coordinates are taken with $x_{1}$ axis parallel to crack face, $\Gamma$ is a contour enclosing the crack tip as in Fig. 3, $T_{i}$ is traction vector, $\dot{u}_{i}$ is displacement rate, and $W^{\prime}$ is strain-rate energy density defined by,

$$
W^{\prime}=\int \sigma_{i j} d \dot{\varepsilon}_{i j}
$$

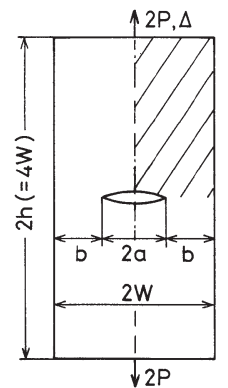

Fig. 2 Center-cracked $(\mathrm{CN})$ specimen for finite element analysis of $J^{\prime}$ 


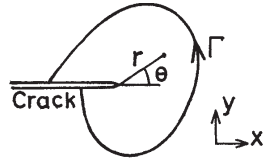

Fig. 3 Path $\Gamma$ for $J$ ' evaluation and coordinates $x_{1} x_{2}$ $(=x y)$.

As is shown in Fig. 4, integration paths with smaller number enclose crack tip nearer to the crack tip; the path with number 1 is the closest to the crack tip and the path with number 13 is along the outer end of the plate. Details of calculation are the same with those of preceding paper ${ }^{28)}$.

Finite element results are shown in Fig. 5. The modified J-integral, $J^{\prime}$ and time $t$ are normalized as,

$$
\begin{gathered}
G^{\prime}=J^{\prime} /\left(b \sigma_{n e t} \dot{\varepsilon}_{n e t}\right) \\
\tau=t \dot{\varepsilon}_{\text {net }} /\left(\sigma_{n e t} / E\right)
\end{gathered}
$$

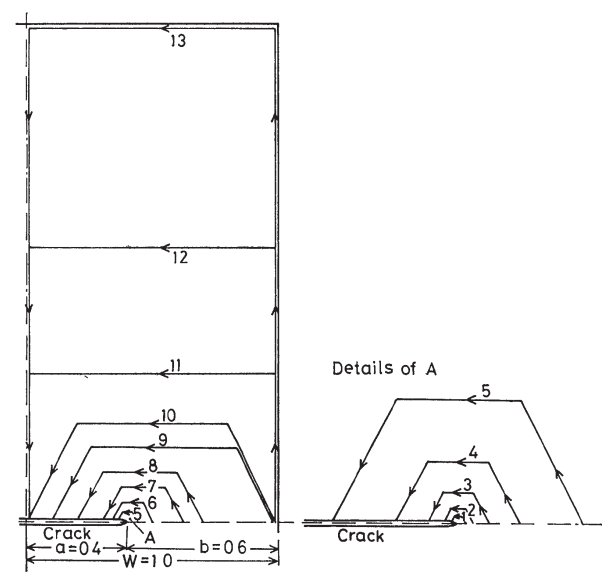

Fig. 4 Integral paths for $J$ ' evaluation.
Where $b$ is the ligament length, $\sigma_{\text {net }}$ is the net section stress and $\dot{\varepsilon}_{n e t}$ is the corresponding net section strain-rate given by,

$$
\dot{\varepsilon}_{n e t}=A \sigma_{n e t}{ }^{n}
$$

A bold solid line in the figure shows the prediction by Eq. (15). White arrows denote the time when elastic strains are comparable with creep strains. In the region where creep strains overwhelm elastic strains and $\tau<10^{-2}$, agreement between the value of $J^{\prime}$ and Eq. (15) is excellent, and the path-independence of $J$ ' holds, which shows the validity of $J$ ' and Eq. (15) under the small-scale creep conditions. The scale of the region where the path-independence holds increases with time $t$. For large loading time $t$ the path-independence of $J$ ' holds for all paths and Eq. (15) no more holds and $J^{\prime}$ value converges to the stationary value $J^{\prime}$ st under the large-scale creep conditions.

For experimental evaluation of $J^{\prime}$, the simple evaluation formulae ${ }^{4), 12), 13)}$ are widely used. For a deeply-cracked plate $J^{\prime}$ can be given by,

$$
J^{\prime}=\{(n-1) /(n+1)\} \dot{\Delta}_{\text {crack }} \sigma_{\text {net }}
$$

where $\dot{\Delta}_{\text {crack }}$ denotes load-point displacement rate due to crack. This equation is applied to shallow cracks also since no other simple and effective equation is available.

The dash-dotted line in the figure shows $J$ ' evaluated by using load-point displacement rate $\dot{\Delta}_{\text {crack }}$ obtained by the finite element analysis. The dashed line shows $J$ ' evaluated by Eq. (55) using load-point displacement rate calculated on the basis of plasticity modification. These lines coincide well for small loading time. The former agrees well with $J$, calculated for outer integral path.

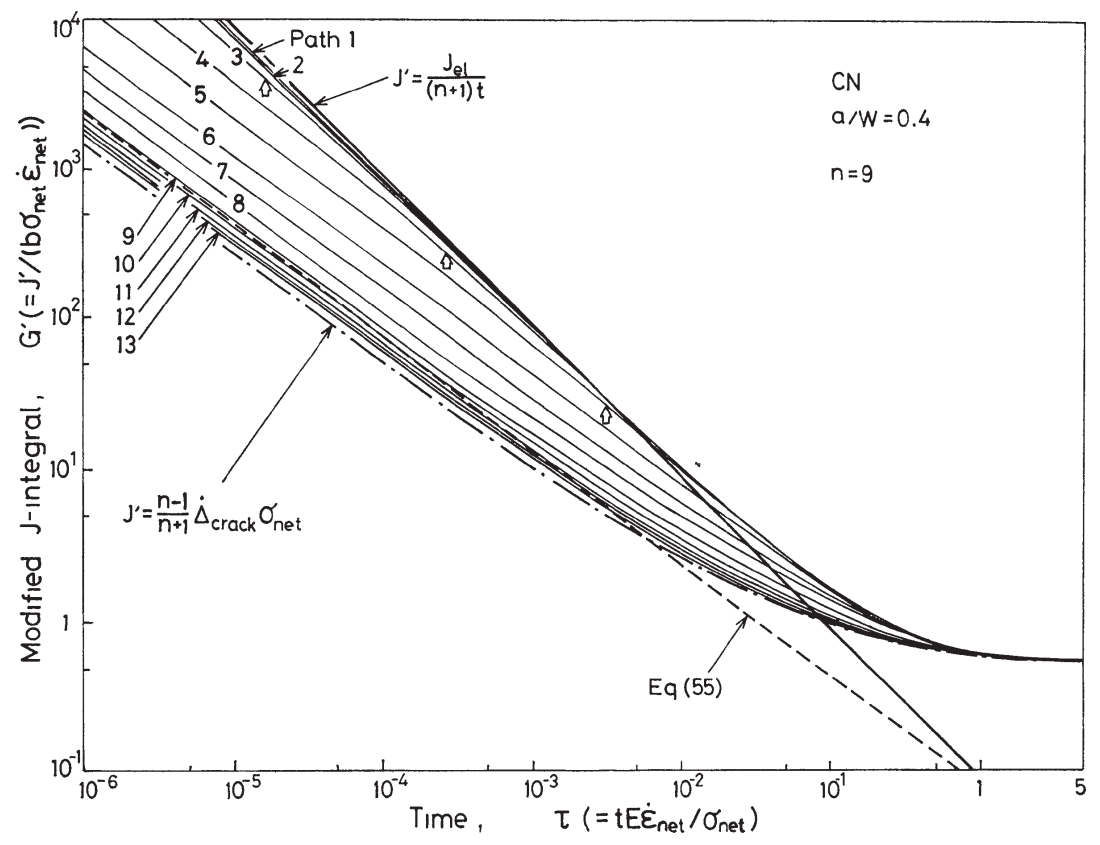

Fig. 5 Change of $J$ 'with loading time $t$ obtained by finite element analysis. 


\section{Discussions}

\subsection{Transition Time from Small-Scale Creep to Large-Scale Creep}

For simplicity, consider a case of Norton's creep $(m=1)$ and constant load $(\alpha=0)$. For small time $t$, the small-scale creep develops and the near-tip $J^{\prime}$ is given by Eq. (15) while $J$ ' converges to the large-scale creep stationary value $J$ 'st for large $t$. As in Fig. 6(a), the transition time $t_{t r}$ from the small-scale creep to the large-scale creep can be obtained by equating Eq. (15) with $J_{s t}^{\prime}$ :

$$
t_{t r}=J_{e l} /\left\{(n+1) J_{s t}^{\prime}\right\}
$$

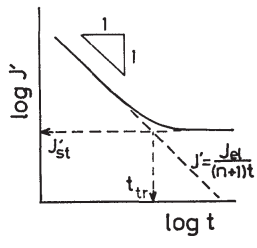

(a)

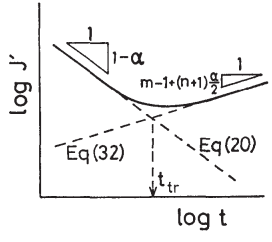

(b)
Fig. 6 A schematic of change in near-tip $J$ '.

When load $P$ is changed keeping other conditions the same, the values of $J_{e l}$ and $J_{s t}^{\prime}$ are proportional to $P^{2}$ and $P^{n+1}$, respectively. Then $t_{t r}$ is proportional $P^{1-n}$. When specimen size is changed keeping the net section stress $\sigma_{\text {net }}$ constant, the values of $J_{e l}$ and $J_{s t}^{\prime}$ are proportional to specimen size, and therefore $t_{t r}$ is independent of the size.

In general case, the near tip $J$ ' under the small-scale creep is expressed by Eq. (20). On the other hand, the value of $J^{\prime}$ under large-scale creep, $J$ 'st for hardening laws (17) and (21) is proportional to a product of $t^{m-1}, P^{n+1}$ and a function of specimen geometry:

$$
J_{s t}^{\prime}=C t^{m-1+(n+1) \alpha / 2} \quad(C \text { : constant })
$$

As in Fig. 6(b), the transition time $t_{t r}$ is given by equating Eq. (32) with Eq. (20):

$$
t_{t r}=\left[(m+\alpha n) B_{2} /\{(n+1) C\}\right]^{2 /\{2 m+(n-1) \alpha\}}
$$

\subsection{Transition Time for Engineering Materials}

Equation (20) predicts that $J^{\prime}$ goes to infinity at load application. Although $J$ ' remains finite due to plasticity as will be discussed in the next section, $J^{\prime}$ under the small-scale creep is very large and therefore $J^{\prime}$ under the large-scale creep may underestimate the near-tip $J$ '.

The effect of small-scale creep is examined for type SUS304 stainless steel. Suppose a center-cracked specimen with relative crack length $2 a / 2 W=16(\mathrm{~mm}) / 26(\mathrm{~mm})$ under tensile nominal stress of $6\left(\mathrm{kgf} / \mathrm{mm}^{2}\right)$ at $650\left({ }^{\circ} \mathrm{C}\right)$. For this condition ${ }^{29)}$, creep exponent $n=7.66, A=6.1 \times 10^{-13}$. The following $J$ ' evaluation formulae under plane stress and large-scale creep are proposed by Ohji, Ogura and Kubo ${ }^{30), 31)}$.

$$
1 / J_{s t}^{\prime}=1 / J_{s}^{\prime}+1 / J_{d}^{\prime}
$$

Here $J_{s}$ and $J_{d}^{\prime}$ denote $J$ ' values under the large-scale creep for a shallow crack and a deep crack, respectively, which are expressed as,

$$
\begin{aligned}
J^{\prime} & =\pi(\pi n / 2)^{(n-1) /(2 n-1)} a \sigma_{n e t} \dot{\varepsilon}_{n e t} \\
J^{\prime}{ }_{d} & =\left\{4 \pi /\left(\pi^{2}-4\right)\right\} n^{-1 / 2} b \sigma_{n e t} \dot{\varepsilon}_{n e t}
\end{aligned}
$$

These equations give

$$
J_{s t}^{\prime} \approx 0.05(\mathrm{kgf} / \mathrm{mm} \cdot \mathrm{hr})
$$

The value of $J_{e l}$ is evaluated from stress intensity factor $K_{I}^{32)}$ using Eq. (7). Young's modulus is $E=1.4 \times 10^{4}\left(\mathrm{kgf} / \mathrm{mm}^{2}\right)$. By substituting these values into Eq. (31), $t_{t r}$ is evaluated as:

$$
t_{t r} \approx 0.3(\mathrm{hr})
$$

This indicates that the effect of small-scale creep is small for the combination of the material and conditions.

Then effect of small-scale creep is examined for the same sized center-cracked specimen made of $1 \mathrm{Cr}-11 / 4 \mathrm{Mo}-1 \mathrm{~V}$ steel under nominal stress of $16\left(\mathrm{kgf} / \mathrm{mm}^{2}\right)$ at $565\left({ }^{\circ} \mathrm{C}\right)$. Creep exponent $n, A$ and $E$ were set at $n=10, A=1.1 \times 10^{-22}$ and $\left.E=1.4 \times 10^{4}\left(\mathrm{kgf} / \mathrm{mm}^{2}\right)^{29}\right)$. The evaluated value of $t_{t r}$ was:

$$
t_{t r} \approx 300(\mathrm{hr})
$$

This result shows a possibility of the small-scale creep effect for low ductility material like $1 \mathrm{Cr}-11 / 4 \mathrm{Mo}-1 \mathrm{~V}$ steel, especially on creep crack initiation.

\subsection{Effect of Plastic Strain}

To examine the effect of plastic strain $\varepsilon_{p l}$, we assume,

$$
\varepsilon_{p l}=D \sigma^{q} \quad(D, q: \text { constants })
$$

Since the creep exponent $n$ and plasticity exponent $q$ are much larger than 1 , the strain singularities for creep and plasticity expressed as $r^{-n /(n+1)}$ and $r^{-q /(q+1)}$ give minor difference. Then for simplicity we assume,

$$
q=n
$$

Consider a case where elastic strains prevail far from the crack tip. Assumptions (1) and (3) in chapter 2 hold. Assumption (2) is replaced by

$$
\varepsilon=\varepsilon_{e l}+\varepsilon_{p l}+\varepsilon_{c r}
$$

At load application, the following plastic strain prevails near the crack tip ${ }^{26), 27)}$.

$$
\varepsilon_{i j}=D\left[J_{e l} /\{I D r\}\right]^{n /(n+1)} \tilde{\varepsilon}_{i j}(\theta)
$$

This equation is coincident with Eq. (6)2, when

$$
D=A F(t)
$$

Denoting the time satisfying Eq. (42) by $t_{p l}$, the existence of the plastic strain is equivalent to time lapse of $t_{p l}$. For example consider a case of Norton's law, from Eqs. (14) and (42),

$$
t_{p l}=D /\{(n+1) A\}
$$

Equation (15) for near-tip $J^{\prime}$ is replaced by,

$$
J^{\prime}=J_{e l} /\left\{(n+1)\left(t+t_{p l}\right)\right\}
$$

Equation (31) for transition time $t_{t r}$ is replaced by,

$$
\begin{aligned}
t_{t r} & =J_{e l} /\left\{(n+1) J_{s t}^{\prime}\right\}-t_{p l} \\
& =J_{e l} /\left\{(n+1) J_{s t}^{\prime}\right\}-D /\{(n+1) A\}
\end{aligned}
$$

As another extreme case, we assume that elastic strains 
can be ignored. Assumption (2) in chapter 2 is replaced by,

$$
\varepsilon=\varepsilon_{p l}+\varepsilon_{c r}
$$

When Norton's law is used for creep strain, the near-tip plastic and creep strains are given by

$$
\begin{aligned}
& \left(\varepsilon_{i j}\right)_{p l}=D\left[J_{p l} /\{I D r\}\right]^{n /(n+1)} \tilde{\varepsilon}_{i j}(\theta) \\
& \left(\varepsilon_{i j}\right)_{c r}=\operatorname{At}\left[J^{\prime}{ }_{s t}^{\prime} /\{I D r\}\right]^{n /(n+1)} \tilde{\varepsilon}_{i j}(\theta)
\end{aligned}
$$

Here $J_{p l}$ denotes plastic J-integral. From similarity between Eqs. (3) and (39) ${ }^{3)-5)}$,

$$
J_{p l} / D=J_{s t}^{\prime} / A
$$

The ratio of $\left(\varepsilon_{i j}\right)_{p l}$ and $\left(\varepsilon_{i j}\right)_{c r}$ is,

$$
\left(\varepsilon_{i j}\right)_{p l} /\left(\varepsilon_{i j}\right)_{c r}=D /(A t)=J_{p l} /\left(J^{\prime}{ }_{s t} t\right)
$$

Denote the time when creep strain $\left(\varepsilon_{i j}\right)_{c r}$ reaches plastic strain $\left(\varepsilon_{i j}\right) p l$ by $t_{c p}$,

$$
t_{c p}=D / A=(n+1) t_{p l}=J_{p l} / J_{s t}^{\prime}
$$

As is seen above, $J_{e l} / J_{s t}^{\prime}$ and $J_{p l} / J_{s t}^{\prime}$ can be time measures when elastic and plastic strains are taken into account.

\section{Concluding Remarks}

This paper is concerned with the small-scale creep condition, where creep region is small and is confined near the crack tip in the early stage of load application. For the small-scale creep condition, an explicit expression of the near-tip modified J-integral, $J^{\prime}$ is introduced. Its validity is shown by finite element analyses. Time measures of the transition from the small-scale creep to the large-scale creep are proposed.

Although 1979 preprint and 1980 paper showed the famous small-scale creep equation (Eq. (15)) and elucidated the whole picture of the transition from the small-scale creep to the large-scale creep, the author was not aware of the important of the research. He thought that he had found just a small missing link. After the publication of these papers, the small-scale effect was extensively discussed ${ }^{33-42)}$. The validity of Eq. (15) was confirmed by several research groups $^{33), 34)}$.

The effect of small-scale creep on cyclic loading was also discussed ${ }^{43), 44)}$

It was shown that the HRR type singular stress and strain rate fields prevail in the vicinity of creep crack tip even in the presence of creep recovery and hardening ${ }^{45), 46)}$, the intensity of the singular fields being enhanced by the change in loads. The $J^{\prime}$ was extended to primary and hardening creep laws ${ }^{5), 36), 37)}$, for which $J^{\prime}$ was denoted by $C^{*}{ }_{h}$ also. Combined effects of the small-scale creep and the dynamic recovery was discussed ${ }^{36,37), 47), 48)}$

The small-scale creep and the transition from the small-scale creep to the large-scale creep were utilized to estimate creep relaxation of notch stress and accumulation of notch strain ${ }^{49)-51)}$.

The small-scale creep results were used also for fracture other than high temperature strength ${ }^{52), 53)}$.
The International Symposium on Materials Science was held at Osaka University in 2001 as an event of the $50^{\text {th }}$ anniversary of the Society of Materials Science, Japan. Taking this occasion, the author drove a car to Kyoto with several Japanese professors to escort Professor J.W. Hutchinson, Professor R.O. Ritchie and Professor S. Suresh. During the visit, we had discussions on fracture mechanics. To the author's surprise Professor Hutchinson knew the small-scale creep paper written originally in Japanese. The English version of the Japanese paper seemed to have been distributed among some researchers working on fracture mechanics. Actually reference to the 1979 preprint written in Japanese is made in a review paper on world academy of structural integrity ${ }^{54)}$.

Professor A. Saxena of Georgia Tech. evaluated the papers and tried to get the results included in ASTM STP volume, but in vain. Afterwards, the author was invited to contribute a chapter on high temperature crack growth in book series on structural integrity. In his response, he proposed dividing the chapter into two parts: one is on creep crack growth to be written by himself and the other is on creep-fatigue crack growth to be written by Professor $\mathrm{T}$. Kitamura who was a top leading researcher on the topics, and including the derivation of the small-scale creep equation in the former one. Therefore, English outline of the small-scale creep equation is available in a book ${ }^{55)}$.

\section{Appendix Evaluation of $J$ ' by combining Simple Evaluation Formula and Plasticity Correction}

The behavior of $J^{\prime}$ is predicted by applying plasticity correction to simple $J$ ' evaluation formula Eq. (30).

For elastic-plastic material plasticity near the crack-tip gives an increase in compliance by $\delta \lambda^{56)}$, which is equivalent to apparent crack growth by $\delta a$ given as,

$$
\delta \lambda=\left\{2 K_{I}^{2} /\left(E P^{2}\right)\right\} \delta a
$$

for mode I and plane stress. The value of $\delta a$ is evaluated using plastic zone radius $r_{Y}$ and yield stress $\sigma_{Y}$ as $^{57) \text {, }}$

$$
\begin{aligned}
\delta a & =\{(n-1) /(n+1)\} r_{Y} \\
& =\{(n-1) /(n+1)\} K_{I}{ }^{2} /\left(2 \pi \sigma_{Y}{ }^{2}\right)
\end{aligned}
$$

Load-point displacement rate due to crack, $\dot{\Delta}_{\text {crack }}$ is given as,

$$
\dot{\Delta}_{\text {crack }}=(d \Delta / d a)(d a / d t)=P(d \lambda / d a)(d a / d t)
$$

Appropriate selection of $\sigma_{Y}$ is a key problem. For simplicity $\sigma_{Y}$ is selected such as $\varepsilon_{c r}=\varepsilon_{e l}$. Then from Eq. (4),

$$
\sigma_{Y}=\{A E F(t)\}^{-1 /(n-1)}
$$

$J^{\prime}$ is evaluated by combining Eq. (30) and $\dot{\Delta}_{\text {crack }}$ obtained from Eqs. (51) through (54):

$$
J^{\prime}=\left[2 m(n-1) K_{I}^{4} \sigma_{n e t} /\left\{\pi(n+1)^{2} \operatorname{EPt}\right\}\right][A E F(t)]^{2 /(n-1)}
$$

From Eqs. (14), (18) and (22), $F(t)$ is proportional to $t^{m}, J^{\prime}$ evaluated by Eq. (55) is proportional to $t^{2 m /(n-1)-1}$, and therefore decreases with time for $n>2 m+1$, increases with 
time for $n<2 m+1$.

The author is grateful to the Society of Materials Science, Japan, for awarding the Paper Award to the 1980 paper. The author is also grateful to the Society, and the chairperson Professor Y. Shimamura and the directors of the Committee on Fracture Mechanics for giving him a chance to describe on the story about the small-scale creep research.

\section{References}

1) M.J. Siverns and A.T. Price, "Crack growth under creep conditions," Nature, Vol. 228, pp. 760-761 (1970).

2) G.J. Neate and M.J. Siverns, "The application of fracture mechanics to creep crack growth," Int. Conf. on Creep and Fatigue in Elevated Temp. Appl., Paper C234 (1974).

3) K. Ohji, K. Ogura and S. Kubo, "Application of the J-integral to creep crack problems," Preprint of JSME, No. 740-11, pp. 207-210 (1974).

4) S. Kubo, "Study on mechanics of creep crack initiation and growth," Ph. D. Thesis, Osaka University, (1975).

5) K. Ohji, K. Ogura and S. Kubo, "Path-independent integral (modified J-integral) in transient creep conditions," Preprint of JSME, No. 750-13, pp. 65-68 (1975).

6) K. Ohji, K. Ogura and S. Kubo, "Mechanical study on creep crack propagation mainly in mode III mode," Trans. of JSME, Ser. A, Vol. 42, No. 354, pp. 350-357 (1976).

7) S. Kubo, K. Ohji and K. Ogura, "States of the arts on studies on creep crack propagation problems," Machine Research, Vol. 28, pp. 1397-1404 (1976); Vol. 29, pp. 27-30 (1977); Vol. 29, pp. 266-270 (1977).

8) K. Ohji, K. Ogura and S. Kubo, "Creep stress analysis of a notched body under longitudinal shear and its application to crack propagation problems", Proc. 1974 Symp. on Mech. Behavior of Materials, JSMS, pp. 455-466 (1974).

9) S. Taira and R. Ohtani, "High Temperature Strength of Materials," (1980), Ohm. Publ.

10) J.D. Landes and J.A. Begley, "A fracture mechanics approach to creep crack growth,” ASTM STP, Vol. 590, pp. 128-148, (1976).

11) K.M. Nikbin, G.A. Webster and C.E. Turner, "Relevance of nonlinear fracture mechanics to creep cracking," ASTM STP, Vol. 601, pp. 47-62 (1976).

12) K. Ohji, K. Ogura and S. Kubo, "Simple estimation method for the modified J-integral for creep crack problems," Preprint of $26^{\text {th }}$ Annual Meeting of JSMS, pp. 137-138 (1977).

13) K. Ohji, K. Ogura and S. Kubo, "Estimates of J-integral in the general yielding range and its application to creep crack problems," Trans. of JSME, Vol. 45, No. 382, pp.
1831-1837 (1978)

14) M.P. Harper and E.G. Ellison, "The use of the C* parameter in predicting creep crack propagation rates", J. Strain Analysis, Vol. 12, pp. 167-179 (1977).

15) E.G. Ellison and G.G. Musicco, "Notch-rupture and crack-growth behavior under creep conditions," in "Subcritical Crack Growth Due to Fatigue, Stress Corrosion and Creep," pp. 403-448 (1984), Elsevier.

16) R. Koterazawa and T. Mori, "Applicability of fracture mechanics parameters to crack propagation under creep condition”, Trans. ASME, J. Eng. Mater. Technol., Vol. 99, pp. 298-305 (1977).

17) K. Ohji, K. Ogura, S. Kubo and Y. Katada, "A study on governing mechanical parameters of creep crack growth rate by using notched round bar specimens with proportional geometry," Proc. 21 $1^{\text {st }}$ Japan Congr. on Materials Research, JSMS, pp. 99-104 (1977).

18) S. Taira, R. Ohtani and T. Kitamura, "Application of J-integral to high-temperature crack propagation: Part I creep crack propagation,” Trans. ASME, J. Eng. Mater. Technol., Vol. 101, pp. 154-161 (1979).

19) K. Ohji, K. Ogura, S. Kubo and Y. Katada, "The application of modified J-integral to creep crack growth in austenitic stainless steel and Cr-Mo-V steel," Int. Conf. Eng. Aspects of Creep, Vol. 2, pp. 9-16 (1980).

20) Int. Conf. Eng. Aspects of Creep, Vol. 2, (1980), I. Mech. E.

21) S. Kubo, K. Ohji and K. Ogura, "An analysis of creep crack propagation on the basis of the plastic singular stress field," Eng. Fracture Mech., Vol.11, No.2, 1979, pp.315-329 (1979).

22) K. Ohji, K. Ogura and S. Kubo, "Stress analysis and modified J-integral in the vicinity of a crack tip under transient creep conditions," Preprint of JSME, No. 790-13, pp. 18-20 (1979).

23) K. Ohji, K. Ogura and S. Kubo, "Stress field and modified J-integral near a crack tip under confined creep deformation,” J. of JSMS, Vol. 29, No. 320, pp.465-471 1089 (1980)

24) H. Riedel and J.R. Rice, "Tensile cracks in creeping solids," ASTM STP, Vol. 700, pp. 112-130, (1980).

25) J.R. Rice, "A path independent integral and the approximate analysis of strain concentration by notches and cracks," Trans. of ASME, J. of Applied Mech., Vol. 35, pp. 379-386 (1968).

26) J.W. Hutchinson, "Singular behavior at the end of a tensile crack in hardening material", J. Mech. Phys. Solids, Vol. 16, No.1, pp. 13-31 (1968).

27) J.R. Rice and G.F. Rosengren, "Plane strain deformation near a crack tip in a power-hardening material", J. Mech. Phys. Solids, Vol. 16, No.1, pp. 1-12 (1968). 
28) K. Ohji, K. Ogura and S. Kubo, "Finite element analysis of the modified J-integral for creep crack problems," Preprint of JSME, No. 780-4, pp. 63-65 (1978).

29) H. Saito, "Creep crack propagation in SUS stainless steel and Cr-Mo-V steel," BS Thesis, Osaka University, (1978).

30) K. Ohji, K. Ogura and S. Kubo, "Analytical and simple evaluation of the modified J-integral," Preprint of $16^{\text {th }}$ Symp. on High Temperature Strength, JSMS, pp. 31-35 (1978).

31) K. Ohji, K. Ogura and S. Kubo, "A simple method for estimation of J-integral and modified J-integral," Trans. of JSME, Ser. A, Vol. 47, No. 416, pp. 400-405 (1981).

32) M. Isida, "Elastic analysis of cracks and stress intensity factor", p. 144 (1976), Baifukan.

33) J.L. Bassani and F.A. McClintock, "Creep relaxation of stress around a crack tip," Int. J. of Solids and Structures, Vol. 17, pp. 479-492, (1981).

34) S.B. Biner and D.S. Wilkinson, "On the stress and strain fields ahead of a stationary crack in creeping solids," Eng. Fracture Mech., Vol. 21, pp. 315-328 (1985).

35) H. Riedel, "Creep deformation at crack tips in elastic-viscoplastic solids," J. of Mechanics and Physics of Solids, Vol. 29, pp. 35-49 (1981).

36) H. Riedel, "Crack-tip stress fields and crack growth under creep-fatigue conditions," ASTM STP, Vol. 803, pp. I-505-I-520 (1983)

37) H. Riedel, "Fracture at High Temperatures," (1987), Springer-Verlag.

38) J.L. Bassani, D.E. Hawk and A. Saxena, "Evaluation of the $C_{t}$ parameter for characterizing creep crack growth rate in the transient regime," ASTM STP, Vol. 995, pp. 7-29, (1989).

39) R. Ehlers and H. Riedel, "A finite element analysis of creep deformation in a specimen containing a macroscopic crack," in "Advances in Fracture Research (Fracture 81)," Vol. 2, pp.691-698, (1981).

40) A. Saxena, "Creep crack growth under non-steady-state conditions," ASTM STP, Vol. 905, pp. 185-201 (1986).

41) A. Saxena, "Fracture mechanics approaches for characterizing creep-fatigue crack growth", JSME Int. J., Ser. A, Vol. 36, pp. 1-20 (1993).

42) A. Saxena, "Nonlinear fracture mechanics for engineers," (1998), CRC Press,

43) K. Ohji, S. Kubo and M. Iwasaki, "Finite element analysis of combined effect of small-scale creep and creep hardening-recovery on near tip stress strain fields," Trans. of JSME, Ser. A, Vol. 52, No. 475, pp.720-726 (1986)

44) K.B. Yoon, A. Saxena and D.L. McDowell, "Influence of crack-tip cyclic plasticity on creep-fatigue crack growth," ASTM STP, Vol. 1131, pp. 367-380 (1992).

45) S. Kubo, "Creep recovery and hardening effects on the stress field near a crack tip under variable loads," Creep in Structures, 3rd IUTAM Symp., Springer, pp.606-610 (1981).

46) S. Kubo, "Effects of creep recovery and hardening on the stress and strain-rate fields near a crack tip in creeping materials," ASTM STP, Vol. 803, pp. I-594-I-614 (1983).

47) S. Kubo, "Combined effect of creep-recovery-hardening and elastic straining on the stress and strain-rate fields near a crack tip in creeping materials," Brown University Report, MRL E-133, pp. 1-35 (1981)

48) C.-P. Leung and D.L. McDowell, "Inclusion of primary creep in the estimation of $\mathrm{C}_{t}$ parameter," Int. J. of Fracture, Vol. 46, pp. 81-104 (1990).

49) K. Ohji, S. Kubo and H. Hirahara, "Estimation of creep relaxation of notch stress by using small-scale creep concept," J. of JSME, Ser. A, Vol. 50, pp.1583-1590 (1984).

50) S. Kubo, K. Ohji and H. Kumamoto, "A simple estimation of notch stress and strain under hardening-creep laws by using the small-scale-creep concept," Int. J. Pressure Vessels \& Piping, Vol. 44, No.2, pp.225-239 (1990).

51) S. Kubo and K. Ohji, "Small-scale and large-scale creep predictions of notch stress and strain under creep Conditions," Creep in Structures IV, IUTAM Symp., pp.363-370 (1991).

52) K. Fakpan, Y. Otsuka, Y. Mutoh, K. Nagata, "Effect of hold time on crack growth behavior of $\mathrm{Pb}$-containing and Pb-free solders," J. Electronic Materials, Vol. 41, No. 11, pp. 3196-3204 (2012).

53) H. Hirakata, T. Kameyama, R. Kotoge, T. Kondo, M. Sakihara and K. Minoshima, "Creep crack propagation in gold submicron films at room temperature," Int. J. of Fracture, Vol. 201, pp. 127-141 (2016).

54) D.M.R. Taplin and S. Saxena, "ICF: the world academy of structural integrity - retrospective and prospective," Strength, Fracture and Complexity, Vol. 7, pp. 101-121 (2011).

55) S. Kubo and T. Kitamura, "Creep-fatigue crack growth," in Comprehensive Structural Integrity Vol. 5, Creep and High-Temperature Failure, pp.273-307, Elsevier, (2003).

56) H. Okamura, "Introduction to linear fracture mechanics", p. 62 (1976), Baifukan.

57) J.R. Rice, "Stresses due to a sharp notch in a work-hardening elastic-plastic material under longitudinal shear", Trans. ASME, J. Appl. Mech., Vol. 34, No. 2, pp. 287-298 (1967). 